\title{
Pyoderma Gangrenosum After Enzymatic Debridement
}

\author{
Mark Duncan, M.D. ${ }^{7}$ and Scott Worswick, M.D. ${ }^{2}$ \\ 'UCLA Department of Medicine, Ronald Reagan UCLA Medical Center, Los Angeles, CA, USA; ${ }^{2}$ UCLA Department of Dermatology, Los Angeles, \\ CA, USA.
}

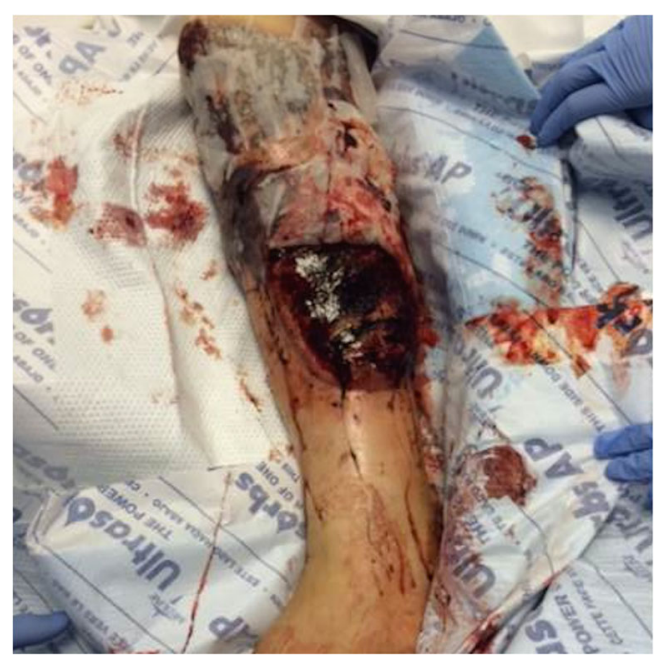

A n 80-year-old man with a history of IgA monoclonal gammopathy presented with a painful ulcerative lesion on his right knee (Fig. 1) that had developed in response to a lanced pustule. Failure of empiric antibiotics led to a punch biopsy, which showed nonspecific acute and chronic inflammation. A diagnosis of pyoderma gangrenosum was made based on negative tissue cultures, characteristic pain, and a classic clinical appearance. Oral cyclosporine resulted in improvement of the lesion. After discharge, he was lost to followup, discontinued the use of cyclosporine, and consulted an outside wound care provider, who initiated a regimen containing topical collagenase for enzymatic debridement. The patient was readmitted with worsening of the lesion (Fig. 2) and hemodynamically significant bleeding. He required blood transfusions but responded well to oral prednisone and avoidance of further mechanical and chemical trauma.

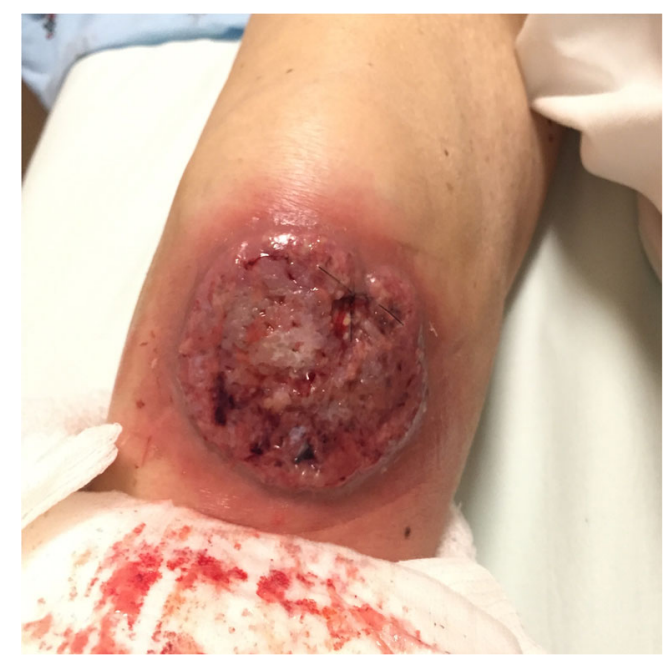

Figure 1 Characteristic lesion of pyoderma gangrenosum. Image of the initial lesion on the patient's right knee.

Received September 3, 2015

Revised October 14, 2015

Accepted October 14, 2015

Published online November 2, 2015
Figure 2 Response after local trauma. Extension of the initial lesion down the right leg after topical collagenase had been applied.

Pyoderma gangrenosum is a neutrophilic dermatosis that commonly presents as an inflammatory nodule or pustule that enlarges and ulcerates. ${ }^{1}$ Mechanical or chemical trauma is known to exacerbate the wound via the mechanism of pathergy. ${ }^{1}$ Associated systemic diseases include inflammatory bowel disease, arthritis, and hematologic disorders; monoclonal gammopathies (predominantly $\operatorname{IgA}$ ) are associated in approximately $10 \%$ of cases. ${ }^{1-4}$

Corresponding Author: Mark Duncan, M.D.; UCLA Department of MedicineRonald Reagan UCLA Medical Center, Los Angeles, CA, USA (e-mail: mduncan@mednet.ucla.edu).

\section{Compliance with Ethical Standards:}

Conflict of Interest: The authors declare that they do not have a conflict of interest.

\section{REFERENCES}

1. Ahronowitz I, Harp J, Shinkai K. Etiology and management of pyoderma gangrenosum: a comprehensive review. Am J Clin Dermatol. 2012;13(3):191-211.

2. Binus AM, Gureshi AA, Li VW, Winterfield LS. Pyoderma gangrenosum: a retrospective review of patient characteristics, comorbidities and therapy in 103 patients. Br J Dermatol. 2011;165(6):1244-50.

3. Powell FC, Schroeter AL, Su WP, Perry HO. Pyoderma gangrenosum: a review of 86 patients. Q J Med. 1985;55(217):173-86.

4. Powell FC, Schroeter AL, Su WP, Perry HO. Pyoderma gangrenosum and monoclonal gammopathy. Arch Dermatol. 1983;119(6):468-72. 